\title{
Biocompatibility of atomic layer-deposited alumina thin films
}

\author{
Dudley S. Finch, ${ }^{1,2}$ Tammy Oreskovic, ${ }^{1}$ Krishna Ramadurai, ${ }^{3}$ Cari F. Herrmann, ${ }^{3,4}$ \\ Steven M. George, ${ }^{4,5}$ Roop L. Mahajan ${ }^{6}$ \\ ${ }^{1}$ National Institute of Standards and Technology, Materials Reliability Division (853), 325 Broadway, \\ Boulder, Colorado 80305-3328 \\ ${ }^{2}$ Department of Materials Science and Engineering, Blacksburg, Virginia 24061 \\ ${ }^{3}$ Department of Mechanical Engineering, University of Colorado at Boulder, Boulder, Colorado 80309-0427 \\ ${ }^{4}$ Department of Chemistry and Biochemistry, University of Colorado at Boulder, Boulder, Colorado 80309-0215 \\ ${ }^{5}$ Department of Chemical and Biological Engineering, University of Colorado, Boulder, Colorado 80309-0424 \\ ${ }^{6}$ ICTAS (Institute for Critical Technology and Applied Science), Department of Engineering Science and Mechanics, \\ Department of Mechanical Engineering, Virginia Tech, Blacksburg, Virginia 24060
}

Received 18 May 2007; revised 25 July 2007; accepted 31 July 2007

Published online 17 December 2007 in Wiley InterScience (www.interscience.wiley.com). DOI: 10.1002/jbm.a.31732

\begin{abstract}
Presented in this paper is a study of the biocompatibility of an atomic layer-deposited (ALD) alumina $\left(\mathrm{Al}_{2} \mathrm{O}_{3}\right)$ thin film and an ALD hydrophobic coating on standard glass cover slips. The pure ALD alumina coating exhibited a water contact angle of $55^{\circ} \pm 5^{\circ}$ attributed, in part, to a high concentration of $-\mathrm{OH}$ groups on the surface. In contrast, the hydrophobic coating (tridecafluoro-1,1,2,2-tetrahydro-octyl-methyl-bis(dimethylamino)silane) had a water contact angle of $108^{\circ} \pm 2^{\circ}$. Observations using differential interference contrast microscopy on human coronary artery smooth muscle cells showed normal cell proliferation on both the ALD alumina and hydrophobic coatings when compared to cells grown on control substrates. These observations suggested good biocompatibility over a period of 7 days in vitro. Using a colorimetric assay technique to assess cell viability,
\end{abstract}

the cellular response between the three substrates can be differentiated to show that the ALD alumina coating is more biocompatible and that the hydrophobic coating is less biocompatible when compared to the control. These results suggest that patterning a substrate with hydrophilic and hydrophobic groups can control cell growth. This patterning can further enhance the known advantages of ALD alumina, such as conformality and excellent dielectric properties for biomicro electro mechanical systems (Bio-MEMS) in sensors, actuators, and microfluidics devices. (C) 2007 Wiley Periodicals, Inc. J Biomed Mater Res 87A: 100-106, 2008

Key words: ALD; atomic layer deposition; biocompatibility; bio-MEMS; conformal coatings; vascular smooth muscle cells

\section{INTRODUCTION}

The primary motivation for this paper is to present results obtained on the biocompatibility of atomic layer-deposited (ALD) alumina $\left(\mathrm{Al}_{2} \mathrm{O}_{3}\right)$ and hydrophobic coatings. While these coatings are increasingly finding their way into micro electro mechanical systems (MEMS) as dielectric layers to prevent electrical shorting, ${ }^{1}$ the work presented here represents the first study to determine the compatibility of ALD coatings for applications in Bio-MEMS. A combination of optical microscopy and an Alamar Blue (AB) assay is used to gain a quantitative measure of the biocompat-

Correspondence to: D.S. Finch; e-mail: dfinch@mse.vt.edu

(C) 2007 Wiley Periodicals, Inc. ibility of ALD alumina-coated glass cover slips with human vascular smooth muscle cells.

The number of biomedical applications for BioMEMS is increasing significantly. These include catheter-based blood pressure sensors, ${ }^{2}$ thermal conductivity sensors, ${ }^{3}$ microfluidic devices, and tools for neurosurgery. ${ }^{4}$ All of these applications represent short-term use. An attractive opportunity is to implant sensors permanently for in vivo monitoring. However, this presents a significant set of challenges both in terms of an appropriate biological response and the reliability of Bio-MEMS. To this end, the need is evident for coatings that both protect the device from a fluidic environment and minimize the impact of the materials on the biological processes that they are measuring.

Many of the processes used to coat MEMS are line-of-sight, which ultimately limits their usefulness 
TABLE I

Summary of Known Properties of Atomic Layer-Deposited Alumina (Compiled From Previous Work ${ }^{10,11}$ )

\begin{tabular}{ccccccc}
\hline $\begin{array}{c}\text { Thickness } \\
(\mathrm{nm})\end{array}$ & $\begin{array}{c}\text { Deposition } \\
\text { temperature }\left({ }^{\circ} \mathrm{C}\right)\end{array}$ & $\begin{array}{c}\text { Resistivity } \\
(\Omega \mathrm{m})\end{array}$ & $\begin{array}{c}\text { Leakage } \\
\text { current }\left(\mathrm{A} / \mathrm{cm}^{2}\right)\end{array}$ & $\begin{array}{c}\text { Electric field used } \\
\text { for leakage current } \\
\text { measurement }(\mathrm{mV} / \mathrm{cm})\end{array}$ & $\begin{array}{c}\text { Catastrophic } \\
\text { breakdown } \\
(\mathrm{mV} / \mathrm{cm})\end{array}$ & $\begin{array}{c}\text { Dielectric } \\
\text { constant, } k\end{array}$ \\
\hline 115 & 177 & $1.00 \mathrm{E}+16$ & $1.00 \mathrm{E}-10$ & 1 & - & 7.5 \\
12 & 177 & $1.00 \mathrm{E}+15$ & $2.00 \mathrm{E}-09$ & 3 & 5.9 \\
\hline $\begin{array}{c}\text { Density } \\
\left(\mathrm{g} / \mathrm{cm}^{3}\right)\end{array}$ & $\begin{array}{c}\text { Refractive } \\
\text { index }(n)\end{array}$ & $\begin{array}{c}\text { RMS } \\
\text { roughness }(\mathrm{nm})\end{array}$ & $\begin{array}{c}\text { FReS (hydrogen } \\
\text { concentration) }\end{array}$ & $\begin{array}{c}\text { RBS (oxygen/ } \\
\text { aluminum ratio) }\end{array}$ & RBS (carbon) & RBS (nitrogen) \\
\hline 3.0 & 1.6 & $0.4 \pm 0.1$ & $6.9 \%$ & $1.56 \pm 0.19$ & Undetected & Undetected \\
\hline
\end{tabular}

RBS = Rutherford backscattering; FReS = forward recoil spectrometry.

when considering raised or three-dimensional structures. A viable alternative is to use atomic layer deposition to produce coatings. ${ }^{5}$ Such coatings are conformal, pinhole free, can be deposited with atomic layer precision at low temperatures, and adhere well to materials used in MEMS devices. ${ }^{1}$

Atomic layer-deposited films are available with a variety of compositions. In this work, we consider ALD alumina because of the previously demonstrated biocompatibility of bulk alumina. ${ }^{6-9}$ In addition, the ability to modify the surface properties by modifying the hydroxyl group concentration (making the surface more hydrophilic or hydrophobic) is of scientific interest in terms of our basic understanding of biocompatibility.

Typical electrical and chemical properties of ALD alumina are shown in Table $\mathrm{I}^{10,11}$ The electrical measurements for ALD alumina were performed on n-type $\mathrm{Si}(100){ }^{10}$ The presence of an approximately 1.2-nm-thick interfacial $\mathrm{SiO}_{2}$ layer between the ALD alumina and the $\operatorname{Si}(100)$ lowers the dielectric constant $(k)$ for the $12 \mathrm{~nm}$-thick ALD alumina film from 7.5 to $5.9 .^{10}$

\section{Atomic layer deposition}

Atomic layer deposition (ALD) utilizes sequential, self-limiting surface reactions of chemical species to deposit thin films. ${ }^{5,12}$ The deposition of alumina $\left(\mathrm{Al}_{2} \mathrm{O}_{3}\right)$ on silicon is achieved by using sequential exposures of trimethylaluminum (TMA, $\left.\mathrm{Al}\left(\mathrm{CH}_{3}\right)_{3}\right)$ and water. ${ }^{13,14} \mathrm{~A}$ schematic drawing of a typical ALD reaction sequence is shown in Figure 1.

In the first reaction, labeled $(\mathrm{A}), \mathrm{Al}\left(\mathrm{CH}_{3}\right)_{3}$ reacts with the hydroxyl $\left(\mathrm{OH}^{*}\right)$ group (the asterisk hereinafter representing the surface-active species), and deposits a monolayer of methyl-terminated aluminum. This reaction stops after all the hydroxyl species have reacted with the TMA. In the second half of the process, labeled (B), water reacts with the $\mathrm{AlCH}_{3}{ }^{*}$ species and deposits a monolayer of hydroxyl groups. The second reaction stops after all the methyl species have reacted with the $\mathrm{H}_{2} \mathrm{O}$. The surface is now ready for another exposure of TMA. These reactions are repeated in a cyclic manner to achieve the desired film thickness.

Because each reaction is self-limiting, the $\mathrm{Al}_{2} \mathrm{O}_{3}$ deposition occurs with atomic layer precision. The number of reaction cycles determines the thickness of the coating. A linear growth rate of $0.12 \mathrm{~nm}$ per cycle was observed during the experiment. This growth rate is the normal growth rate for ALD alumina at $177^{\circ} \mathrm{C}^{14}$ Atomic force microscopy (AFM) images revealed that the $\mathrm{Al}_{2} \mathrm{O}_{3}$ films on $\mathrm{Si}(100)$ were extremely flat and uniform (see Table I). From Rutherford backscattering spectroscopy (RBS), the levels of carbon and nitrogen in the alumina films were below the limits of detectability. ${ }^{11}$

After completing the $\mathrm{H}_{2} \mathrm{O}$ reaction, the $\mathrm{Al}_{2} \mathrm{O}_{3}$ film is left with a very high coverage of $\mathrm{AlOH}^{*}$ groups on the surface. At room temperature, this hydroxyl coverage may be almost twice as large as the coverage of hydroxyl groups on $\mathrm{SiO}_{2}$ surfaces, generally accepted to be approximately $4.6 \times 10^{14} \mathrm{OH}$

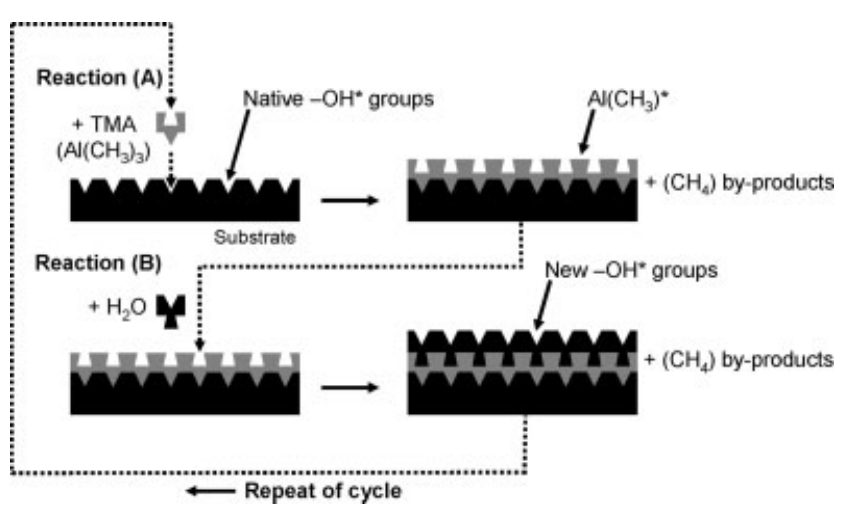

Figure 1. ALD reaction scheme showing two self-limiting half reactions, (A) and (B), which combine to give $\mathrm{Al}_{2} \mathrm{O}_{3}$ coatings of well-defined chemistry and thickness, in which the $\mathrm{Al}\left(\mathrm{CH}_{3}\right)^{*}$ and the $-\mathrm{OH}^{*}$ groups are the surface reactive species and $\mathrm{CH}_{4}$ is the reaction by-product. 
groups $/ \mathrm{cm}^{2}{ }^{15-17}$ This population of $\mathrm{AlOH}^{*}$ groups was utilized during a gas phase technique to functionalize the surface and render it highly hydrophobic. This technique, described in detail elsewhere, ${ }^{18}$ comprises an ALD alumina seed layer and the subsequent adsorption of a functional hydrophobic monolayer using a non-chlorinated precursor. The precursor was synthesized from chlorosilane available commercially (Gelest, Morrisville, PA).

\section{MATERIALS AND EXPERIMENTAL METHODS}

\section{Materials}

Commercially available borosilicate microscope glass cover slips were used to compare uncoated surfaces with those coated with ALD alumina and a hydrophobic coating. Glass cover slips were chosen primarily because of size limitations in the ALD reactor and because of their widespread use in cell biology.

\section{Atomic layer deposition}

ALD was performed in a viscous flow reactor. ${ }^{19}$ Although there are no theoretical limitations to the size of the reactor that can be used, the flow tube or reaction zone used for these experiments was a stainless steel tube 50.8 $\mathrm{cm}$ long with a 3.5-cm inner diameter, heated externally with ceramic heaters. The tube had a reaction region 2.5 $\mathrm{cm}$ wide by $18 \mathrm{~cm}$ long in which seven glass cover slips were placed and subsequently heated by radiation and convection from the hot walls.

The system utilized a viscous flow of nitrogen carrier gas to transport the reactants to the substrate and to purge the reaction products from the flow tube. A mass flow controller was used to regulate the nitrogen flow to a total of $\sim 200 \mathrm{sccm}$. These conditions yielded a $\sim 2.5 \mathrm{~m} / \mathrm{s}$ flow velocity in the reaction chamber. The reactants were alternately pulsed into the gas flow using pneumatic valves controlled by a computer program. The glass substrates were coated with $500 \mathrm{AB}$ cycles (see Fig. 1) at $177^{\circ} \mathrm{C}$. These $500 \mathrm{AB}$ cycles correspond to $\sim 60 \mathrm{~nm}$ thickness of ALD alumina. The choice of temperature is based on the optimum deposition rate for the process. In practice, the process can be applied at close to room temperature with a resultant increase in cycle time due to decreased reactivity and longer purge times. ${ }^{11}$

To produce the hydrophobic variation, an ALD alumina seed layer was deposited at $140^{\circ} \mathrm{C}$ using the approach described above. This $\mathrm{Al}_{2} \mathrm{O}_{3}$ layer provides a dense and uniform concentration of surface $-\mathrm{OH}$ groups. A hydrophobic precursor, tridecafluoro-1,1,2,2-tetrahydrooctyl-methyl-bis(dimethylamino)silane $\left(\mathrm{C}_{8} \mathrm{~F}_{13} \mathrm{H}_{4}\left(\mathrm{CH}_{3}\right) \mathrm{Si}(\mathrm{N}\right.$ $\left.\left.\left(\mathrm{CH}_{3}\right)_{2}\right)_{2}\right)$, was then chemically bonded to the surface hydroxyl groups on the ALD seed layer. On flat substrates, this procedure produces a film that is highly hydrophobic with a water contact angle of $108^{\circ} .^{18}$ The typical thickness of the outermost hydrophobic layer is $\sim 1 \mathrm{~nm}$, based on the knowledge of the chemical structure of the precursor as well as high resolution TEM studies. ${ }^{18}$

\section{Cell culture}

Human coronary artery smooth muscle cells (CASMC) were obtained commercially (Cambrex Bio Science, Wakersville, MD). The cells were cultured in smooth muscle cell media (SMCM) and supplemented with $5.5 \mathrm{mM}$ glucose, $5 \%$ fetal bovine serum (FBS), $50 \mu \mathrm{g} / \mathrm{mL}$ gentamicin, 50 $\mathrm{ng} / \mathrm{mL}$ amphotericin-B, $5 \mu \mathrm{g} / \mathrm{mL}$ insulin, $2 \mathrm{ng} / \mathrm{mL}$ human recombinant fibroblast growth factor (hFGF), and $0.5 \mathrm{ng} /$ $\mathrm{mL}$ human recombinant epidermal growth factor (hEGF). The cells were then incubated in a humidified environment at $37^{\circ} \mathrm{C}$ in $5 \% \mathrm{CO}_{2}$ and $95 \%$ air.

At $80 \%$ confluency, the cells were rinsed in HEPES, an organic chemical buffer, and then detached from the surface of T75 cell culture flasks using a $0.025 \%$ trypsin in ethylene diamine tetra acetic acid (EDTA) solution for 2 min. The CASMCs were resuspended in a trypsin neutralizing solution, centrifuged into pellet form and resuspended in smooth muscle cell media as a cell suspension for the experiments. Cells that were available at passage numbers 7 and 8 were used in the experiments. Cell passaging or splitting is a technique that keeps cells alive and growing under cultured conditions for extended periods of time. ${ }^{20}$

\section{Cell proliferation and measurement of cell activity}

The effects of proliferation of coronary artery smooth muscle cells on ALD alumina-coated substrates were compared to the same cell batch grown on glass control substrates. This comparison assessed whether biologic function was retained on the ALD alumina-coated substrates. An Alamar Blue (AB) (Alamar Blue ${ }^{\mathrm{TM}}$, Biosource International, Camarillo, CA; Alamar Blue assay, US patent 5,501,959, Trek Diagnostic Systems, Cleveland, OH) assay was used to determine cell proliferation viability/activity over 7 days of growth on the various substrates. The AB assay, which incorporates a redox indicator that changes color in response to metabolic activity, is commonly used to assess quantitatively the viability and/or proliferation of mammalian cells and micro-organisms. ${ }^{21}$ As cells grow, the chemical reaction of the growth media causes the Alamar Blue to change from a blue (oxidized) to a red (reduced) form. The color change is due to the uptake of oxygen by the cells in the media and its replacement by hydrogen.

All substrates were degreased by soaking in 100\% ethanol for 10 min each, dried under a laminar flow hood and sterilized under a UV lamp for $20 \mathrm{~min}$ on both sides before exposure to cells. Experiments were performed using untreated six-well cell culture plates. Each well was considered an individual data point. The number of cells plated in each experiment was determined using a standard commercially available hemocytometer. Initially, $125 \mu \mathrm{L}$ of cell suspension was added to each substrate surface in the six-well cell culture plates and incubated for 


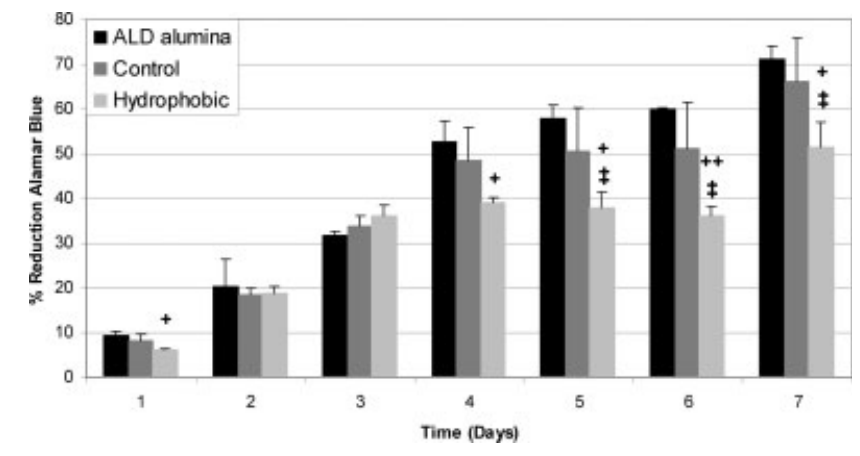

Figure 2. Reduction in Alamar Blue (\%) over 7 days, comparing ALD alumina-coated cover slips with hydrophobic-coated cover slips and uncoated cover slips (control). Data is represented as a bar for each time point and reported with the associated mean \pm standard deviation (SD). Data is reported as mean $\pm \mathrm{SD}$, where $t$ shows a significance test for cases versus control, $(\$ p<0.05)$ and + shows a significance test for ALD alumina versus hydrophobic $(+p<0.05$ and $++p<0.01)$.

fifteen minutes prior to the addition of $2 \mathrm{~mL}$ of SMCM and supplements.

The optimum cell-seeding density was determined to be $6 \times 10^{4}$ cells per well from a standard calibration curve obtained over $48 \mathrm{~h}$ using concentrations ranging from 0.5 to $36 \times 10^{4}$ cells $/ \mathrm{mL}$. Alamar Blue was added to the cell culture wells at $1: 10(\mathrm{v} / \mathrm{v})$ ratio and incubated over the 5 days. Aliquots of $200 \mu \mathrm{L}$ of the Alamar Blue medium were transferred at each time point to a 96-well cell culture plate and absorbance read at 570 and $600 \mathrm{~nm}$ using a commercially available automated plate reader. Absorbance was recorded every $24 \mathrm{~h}$ over a period of 7 days.

\section{Statistical analysis}

All experiments were performed for 7 days in triplicate and repeated at least twice. Cell proliferation data were analyzed using standard analysis of variance (ANOVA) techniques (Graph Pad In Stat, GraphPad Software, San Diego, CA) and Students Newman-Keuls post-hoc comparisons, with a value showing $p<0.05$ considered significant. The mean \pm standard deviation and \pm standard error of the means are presented in the graphs.

\section{Optical microscopy}

Optical micrographs of the proliferating vascular smooth muscle cells were recorded using a differential interference contrast (DIC) microscope equipped with a digital camera. Cells were imaged directly on the cover slip. These were prepared by removing the cover slip with cells attached from the media and gently rinsing them to minimize cell detachment in distilled deionized water. This was immediately followed by recording optical micrographs.

\section{RESULTS AND DISCUSSION}

\section{Alamar Blue assay}

The main objective of using the Alamar Blue assay is to quantify the proliferation of the human vascular smooth muscle cells on the ALD alumina- and hydrophobic-coated glass cover slips. The uncoated borosilicate glass cover slips served as a control. As stated previously, a cell plating density of $6 \times$ $10^{4}$ cells $/ \mathrm{mL}$ was chosen from the standard curve experiment. The cell suspensions were placed on the coated and uncoated cover slips (control samples) as per the procedure described above under Cell Proliferation and Measurement of Cell Activity.

The experiments were performed in triplicate to take into account the variability within a particular run. The results are presented as a percent reduction $\mathrm{AB}$ of the two coated substrates and the control shown in Figure 2. The difference in $A B$ reduction between the control and the two coated substrates (ALD alumina and hydrophobic) as a function of time is shown in Figure 3. These results clearly demonstrate the different responses of the two substrates versus the control.

Figures 2 and 3 show that the percentage of Alamar Blue reduction for the ALD alumina-coated cover slips is slightly higher than that of the uncoated glass cover slips. However, the difference is not statistically significant. In the case of the hydrophobic coating, the $\mathrm{AB}$ reduction was found to be statistically lower $(p<0.05)$, showing a difference from the control glass cover slip and the ALD alumina-coated substrates after 4 days. With reference to Figure 3, the ALD alumina-coated substrate shows a slight decrease at day 7 . This decrease is most likely associated with contact inhibited cell growth and is indicative of a higher cell proliferation rate on ALD alumina.

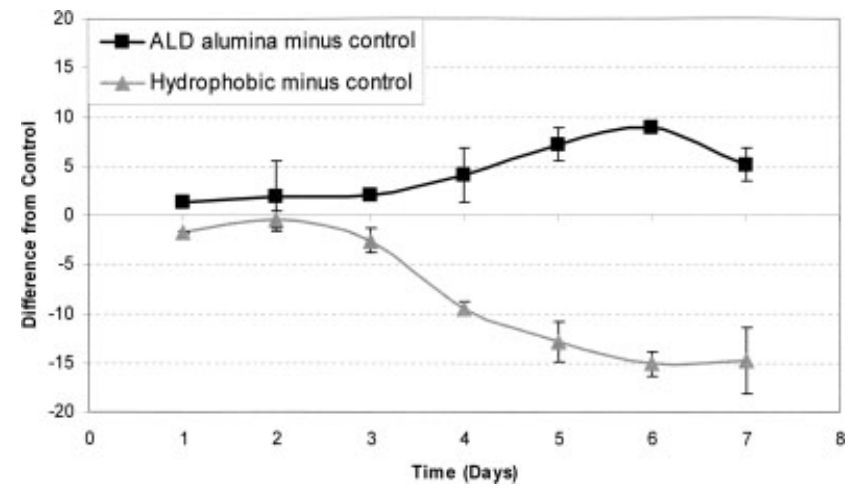

Figure 3. Difference (mean \pm standard error \%) from control for ALD alumina and hydrophobic coating versus time (days). 


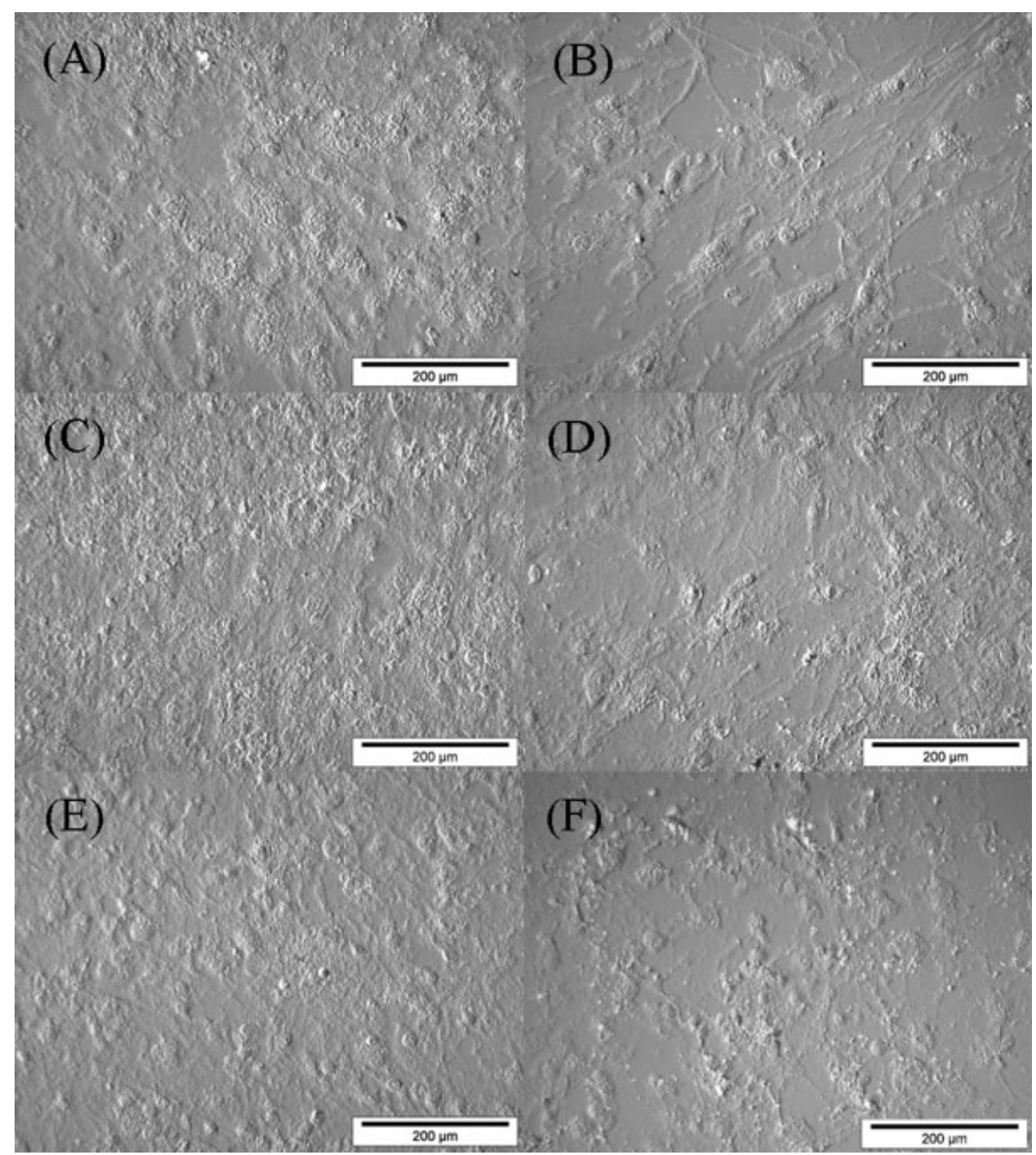

Figure 4. Differential interference contrast micrographs of human vascular smooth muscle cells, comparing cell proliferation on ALD alumina-coated glass cover slips with uncoated (control) glass cover slips. (A) ALD alumina coating after one day, (B) ALD alumina coating after 5 days, (C) hydrophobic coating after one day, (D) hydrophobic coating after 5 days, (E) control after one day, and (F) control after 7 days.

\section{Microscopy}

The images of the cells on the substrates in Figure 4 , recorded after 1 and 5 days of exposure, show that the human coronary artery smooth muscle cells have adhered to the coated substrates and have formed a coherent layer. Proliferation rates were typical for in vitro conditions, whereby cells spread randomly with time on the surface without any organized structure when compared to the elongated morphology that would be observed in vivo.

The cells consistently appeared to proliferate equally or more rapidly during the first $24 \mathrm{~h}$ on the ALD alumina-coated glass cover slips than on the uncoated control as indicated by the higher cell density. This result is in contrast with the Alamar Blue results that showed no statistical difference between the two samples after $24 \mathrm{~h}$. At day 7, some visual differences were apparent between the samples, with the cells attached to the ALD alumina surface appearing less densely populated than the control, suggesting an increase in cell spreading and average cell size.

As mentioned under the section titled Atomic layer deposition of the Introduction, there is a large concentration of hydroxyl groups present on the surface of the ALD alumina, which contributes to its hydrophilicity. The measured contact angle for ALD alumina is $55^{\circ} \pm 5^{\circ}$. This contact angle is very similar to the contact angle for the glass cover slips of $61^{\circ} \pm$ $2^{\circ}$. The hydrophilic nature of the ALD coating, typically desirable for cell adhesion and growth, ${ }^{22,23}$ can explain the observed results. Increasing the contact angle to $108^{\circ}$ by incorporating tridecafluoro-1,1,2,2-tet- 
rahydro-octyl-methyl-bis(dimethylamino) silane on the surface of the ALD alumina had a statistically significant impact on the $\mathrm{AB}$ reduction.

These results show that modifying the hydrophilicity of the surface coating impacts cell viability. ALD alumina was shown to be biocompatible. The advantage of using ALD, aside from ALD being a conformal coating method, is that the surface properties can be tailored to a given application. Further work is underway to determine quantitatively the impact of changing surface chemistry and electrical properties on cell proliferation and growth.

\section{CONCLUSIONS}

Cell adhesion and growth have been successfully demonstrated on atomic layer-deposited alumina thin films on glass cover slips. The use of an Alamar Blue assay as a measure of biocompatibility suggests that coating glass cover slips with $60 \mathrm{~nm}$ of ALD alumina results in very similar levels of biocompatibility when compared with the uncoated glass samples. Modifying the ALD coating via the addition of hydrophobic groups leads to a statistically significant reduction in Alamar Blue, which is interpreted as a reduction in biocompatibility of the coating. These observations pave the way for the adoption of ALD alumina coatings for Bio-MEMS and other devices coming into contact with biological media.

Further work is required to expand this study using a variety of other materials relevant to Bio-MEMS, such as polysilicon. The possibility also remains of whether or not ALD alumina can be applied to gold structures that are commonly used in MEMS devices, and whether or not these ALD alumina-coated structures are biocompatible. In addition, no evaluations have been made to determine the long-term performance of these coatings. Questions also remain as to why the ALD alumina-coated samples did not show a more significant improvement over the uncoated glass cover slips, and whether or not there is a direct relationship between contact angle and biocompatibility. Consequently, there is a need for further investigation in terms of optimizing the ALD coating for the best chemical and surface properties.

We thank Professors Michael Stowell and Maria Pagratis of the Department of Molecular, Cellular and Developmental Biology at the University of Colorado at Boulder for assistance in performing the Alamar Blue assay experiments, and Professor Yiqun Shellman of the University of Colorado, Health Sciences, Denver, Colorado, for discussions relating to the interpretation of the biocompatibility tests and cell morphology. Finally, we acknowledge Heidi Haehlen's time and energy spent in editing the manuscript.
All views expressed in this article are those of the authors and of others to whom attribution is given and are not necessarily those of NIST or of any of the institutions cited herein. Certain commercial equipment, instruments, or materials are identified in this article to specify experimental or theoretical procedures. Such identification does not imply recommendation by any of the host institutions of the authors, nor does it imply that the equipment or materials are necessarily the best available for the intended purpose.

\section{References}

1. Hoivik ND, Elam JW, Linderman RJ, Bright VM, George SM, Lee YC. Atomic layer-deposited protective coatings for micro-electromechanical systems. Sensor Actuat A 2003;103: 100-108.

2. Bistue G, Elizalde JG, Garcia-Alonzo I, Olaizola S, Castano, E, Gracia FJ, Garcia-Alonso A. A micromachined pressure sensor for biomedical applications. J Micromech Microeng 1997; 7:244-246.

3. Rousell P, Lysenko V, Remaki B, Delhomme G, Dittmar A, Barbier D. Thick oxidised porous silicon layers for the design of a biomedical thermal conductivity microsensor. Sensor Actuat 1999;74:100-103.

4. Roy S, Ferrara LA, Fleischman AJ, Benzel EC. Microelectromechanical systems and neurosurgery: A new era in a new millennium. Neurosurgery 2001;49:779-797.

5. George SM, Ott AW, Klaus JW. Surface chemistry for atomic layer growth. J Phys Chem 1996;100:13121-13131.

6. Engelhardt A, Salzer M, Zeibig A, Locke H. Experiences with $\mathrm{Al}_{2} \mathrm{O}_{3}$ implantations in humans to bridge resection defects. J Biomed Mater Res 1975;9:227-232.

7. Heimke G, Griss P, Jentschura G, Werner E. Direct anchorage of $\mathrm{Al}_{2} \mathrm{O}_{3}$-ceramic hip components: Three years of clinical experience and results of further animal studies. J Biomed Mater Res 1998;41:519-526.

8. Hayashi K, Matsuguchi N, Uenoyama K, Kanemaru T, Sugioka Y. Evaluation of metal implants coated with several types of ceramics as biomaterials. J Biomed Mater Res 1989; 11:1247-1259.

9. Takami Y, Nakazawa T, Makinouchi K, Glueck J, Nose Y. Biocompatibility of alumina, ceramic and polyethylene as materials for pivot bearings of a centrifugal blood pump. J Biomed Mater Res 1997;36:381-386.

10. Groner MD, Elam JW, Fabreguette FH, George SM. Electrical characterization of thin $\mathrm{Al}_{2} \mathrm{O}_{3}$ films grown by atomic layer deposition on silicon and various metal substrates. Thin Solid Films 2002;413:186-197.

11. Groner MD, Fabreguette FH, Elam JW, George SM. Low temperature $\mathrm{Al}_{2} \mathrm{O}_{3}$ atomic layer deposition. Chem Mater 2004;16: 639-645.

12. Leskela M, Ritala M. Atomic layer deposition (ALD): From precursors to thin film structures. Thin Solid Films 2002;409: 138-146.

13. Dillon AC, Ott AW, George SM, Way JD. Surface chemistry of $\mathrm{Al}_{2} \mathrm{O}_{3}$ deposition using $\mathrm{Al}\left(\mathrm{CH}_{3}\right)_{3}$ and $\mathrm{H}_{2} \mathrm{O}$ in a binary reaction sequence. Surf Sci 1995;322:230-242.

14. Ott AW, Klaus JW, Johnson JM, George SM. $\mathrm{Al}_{2} \mathrm{O}_{3}$ thin film growth on $\mathrm{Si}(100)$ using binary reaction sequence chemistry. Thin Solid Films 1997;292:135-144.

15. Cameron MA, Gartland IP, Smith JA, Diaz SF, George SM. Atomic layer deposition of $\mathrm{SiO}_{2}$ and $\mathrm{TiO}_{2}$ in alumina tubular membranes: Pore reduction and effect of surface species on gas transport. Langmuir 2000;16:7435-7444. 
16. Sneh O, George SM. Thermal stability of hydroxyl groups on a well-defined silica surface. J Phys Chem 1995;99:46394647.

17. Knozinger H, Ratnasamy P. Catalytic alumina surface models and characterization of surface sites. Catal Rev Sci Eng 1978; 17:31-70.

18. Herrmann CF, Del Rio FW, Bright VM, George SM. Conformal hydrophobic coatings prepared using atomic layer deposition seed layers and non-chlorinated hydrophobic precursors. J. Micromech Microeng 2005;15:984992.

19. Elam JW, Groner MD, George SM. Viscous flow reactor with quartz crystal microbalance for thin film growth by atomic layer deposition. Rev Sci Instrum 2002;73:2981-2987.
20. Spector DL, Goldman RD, Leinwand LA. Cells: A Laboratory Manual. NY: Cold Spring Harbor Laboratory Press; 1998. Chapter 2.

21. Nakayama GR, Caton MC, Nova MP, Parandoosh Z. Assessment of the Alamar Blue assay for cellular growth and viability in vitro. J Immunol Methods 1997;204:205-208.

22. Webb K, Hlady V, Tresco PA. Relative importance of surface wettability and charged functional groups on NIH 3T3 fibroblast attachment, spreading, and cytoskeletal organization. J Biomed Mater Res 1998;41:422-430.

23. Altankov G, Grinnell F, Groth T. Studies on the biocompatibility of materials: Fibroblast reorganization of substratumbound fibronectin on surfaces varying in wettability. J Biomed Mater Res 1996;30:385-391. 